\title{
Lung Transplantation for Cystic Fibrosis
}

Frederick R. Adler1, Paul Aurora ${ }^{2,3}$, David H. Barker ${ }^{4}$, Mark L. Barr ${ }^{5}$, Laura S. Blackwell ${ }^{4}$, Otto H. Bosma $^{6}$, Samuel Brown7, D. R. Cox ${ }^{8}$, Judy L. Jensen7, Geoffrey Kurland ${ }^{9}$, George D. Nossent ${ }^{6}$, Alexandra L. Quittner ${ }^{4}$, Walter M. Robinson ${ }^{10}$, Sandy L. Romero ${ }^{4}$, Helen Spencer ${ }^{2}$, Stuart C. Sweet ${ }^{11}$, Wim van der Bij ${ }^{6}$, J. Vermeulen ${ }^{6}$, Erik A. M. Verschuuren ${ }^{6}$, Elianne J. L. E. Vrijlandt' ${ }^{6}$, William Walsh', Marlyn S. Woo ${ }^{12}$, and Theodore G. Liou ${ }^{7}$

\begin{abstract}
${ }^{1}$ Departments of Mathematics and Biology, and ${ }^{7}$ Division of Respiratory, Critical Care and Occupational Pulmonary Medicine, Department of Internal Medicine, University of Utah, Salt Lake City, Utah; ${ }^{2}$ Cardiothoracic Transplant Unit, Great Ormond Street Hospital for Children NHS Trust, London; ${ }^{3}$ Portex Unit: Respiratory Physiology and Medicine, UCL, Institute of Child Health, London, United Kingdom; ${ }^{4}$ Department of Psychology, University of Miami, Coral Gables, Florida; ${ }^{5}$ Division of Cardiothoracic Surgery, University of Southern California, Los Angeles, California; ${ }^{6}$ Department of Pulmonary Diseases, Paediatrics and Epidemiology, the Lung Transplant Team, University Medical Center Groningen (UMCG), Groningen, The Netherlands; ${ }^{8}$ Nuffield College, Oxford, United Kingdom; ${ }^{9}$ Division of Pediatric Pulmonology, Children's Hospital of Pittsburgh, Pittsburgh, Pennsylvania; ${ }^{10}$ Center for Applied Ethics, Newton, Massachusetts; ${ }^{11}$ Department of Pediatrics, Washington University, St. Louis, Missouri; ${ }^{12}$ Cardiothoracic Transplant Team, Division of Pediatric Pulmonology, Children's Hospital of Los Angeles, Los Angeles, California
\end{abstract}

Lung Transplantation for Cystic Fibrosis:

Problems, Controversy, and Possible Solutions

William Walsh, Geoffrey Kurland, and Theodore G. Liou

Pediatric Lung Transplantation for Cystic Fibrosis:

Overview and Historical Perspective

Stuart C. Sweet

Operative and Perioperative Considerations in

Lung Transplantation

Samuel Brown and Mark L. Barr

(Non)-Adherence in Cystic Fibrosis and Lung

Transplantation

G. D. Nossent, O. H. Bosma, E. A. M. Verschuuren,

K. Vermeulen, E. J. L. E. Vrijlandt, and $W$. van der Bij

The Importance of Measuring Health-related Quality of Life

Alexandra L. Quittner, David H. Barker,

Laura S. Blackwell, Sandy L. Romero, and Marlyn S. Woo

Three Sociohistorical Challenges to Improving

Lung Transplantation for Cystic Fibrosis

W. M. Robinson

Alternate Models of Selection for Lung

Transplantation: What Distinguishes

the British System?

Paul Aurora and Helen Spencer

\footnotetext{
(Received in original form August 16, 2009; accepted in final form September 24, 2009) A roundtable discussion from the International Perspectives on Lung Transplantation: Adult and Pediatric Outcomes for Cystic Fibrosis Conference, Lansdowne, VA, June 25-26, 2008.

Support for the Lansdowne Conference and the publication of this roundtable discussion was provided by the Ben B. and Ira M. Margolis Family Foundation of Utah, the National Institutes of Health/National Heart, Lung and Blood Institute.

Authors are listed in alphabetical order except for the corresponding, senior author.

Correspondence and requests for reprints should be addressed to Theodore G. Liou, M.D., Associate Professor, Division of Respiratory, Critical Care and Occupational Pulmonary Medicine, Department of Internal Medicine, University of Utah, 26 North Medical Drive, Salt Lake City, UT 84112. E-mail: ted.liou@utah.edu

Proc Am Thorac Soc Vol 6. pp 619-633, 2009

DOI: $10.1513 /$ pats.2009008-088TL

Internet address: www.atsjournals.org
}

Some Comments on Study Design

D. R. Cox

Lung Transplantation and Cystic Fibrosis Lung

Disease: Questions and Challenges

Marlyn S. Woo and Geoffrey Kurland

Lung transplantation is a complex, high-risk, potentially life-saving therapy for the end-stage lung disease of cystic fibrosis (CF). The decision to pursue transplantation involves comparing the likelihood of survival with and without transplantation as well as assessing the effect of wait-listing and transplantation on the patient's quality of life. Although recent population-based analyses of the US lung allocation system for the CF population have raised controversies about the survival benefits of transplantation, studies from the United Kingdom and Canada have suggested a definite survival advantage for those receiving transplants. In response to these and other controversies, leaders in transplantation and CF met together in Lansdowne, Virginia, to consider the state of the art in lung transplantation for CF in an international context, focusing on advances in surgical technique, measurement of outcomes, use of prognostic criteria, variations in local control over listing, and prioritization among the United States, Canada, the United Kingdom, and The Netherlands, patient adherence before and after transplantation and other issues in the broader context of lung transplantation. Finally, the conference members carefully considered how efforts to improve outcomes for lung transplantation for CF lung disease might best be studied. This Roundtable seeks to communicate the substance of our discussions.

Keywords: lung transplantation; survival; quality of life; study design; adherence

\section{Lung Transplantation for Cystic Fibrosis: Problems, Controversy, and Possible Solutions}

\author{
William Walsh, Geoffrey Kurland, and \\ Theodore G. Liou
}

Transplantation is a complex rescue therapy used in both adult and pediatric patients with terminal lung disease with frequently dramatic results. Patients with cystic fibrosis (CF) comprise a minority of infants, toddlers, and adults undergoing lung transplantation, but patients with $\mathrm{CF}$ remain the majority of older children receiving this therapy (1). The availability of a CF Patient Registry organized by the Cystic Fibrosis Founda- 
tion in the United States has facilitated the study of patients of all ages with CF who have received lung or heart-lung transplants. Yet, even for CF, the heterogeneity of candidates, complexity of the procedure, variability of pre- and posttransplant care, low sample size at some individual centers, and considerable demand for the therapy among patients and families have limited the formal evaluation of efficacy.

One study of efficacy of lung transplantation focused on pediatric patients with CF, "Lung Transplantation and Survival in Children with Cystic Fibrosis" by Liou and colleagues in November of 2007 (2), led to considerable controversy following its publication. Based on a retrospective analysis, the authors concluded that few children with CF derived a survival benefit from lung transplantation. Using pooled data from the United Network for Organ Sharing (UNOS) and CF Foundation registries to generate a multivariate survival model incorporating transplantation, Liou and colleagues predicted improved survival for only 5 of 514 listed and only 1 of 248 transplanted children with CF between 1992 and 2002. To reconcile their data with the perception by the transplant community, that pediatric lung transplantation for $\mathrm{CF}$ was in fact efficacious, the authors suggested a prospective randomized controlled trial (RCT) of the procedure. In the accompanying editorial, Allen and Visnor proposed revision of organ allocation, which had previously been based on time on waiting list (3).

Sweet and colleagues (4) disputed the statistical methodology and inferences of Liou and colleagues, whereas Egan stated that a more recently (2005) established system for allocating organs by Lung Allocation Score (LAS-a score that distributes organs on the basis of model-predicted benefit from transplantation) made the assessment of efficacy of transplantation based on prior allocation systems irrelevant (5). Sweet, Aurora, and Egan all emphasized prior experience in Great Britain, which suggested improved survival of transplanted versus listed patients (6-8), whereas Sweet and colleagues emphasized that allocation by LAS (currently used for recipients older than 12) should resolve most problems with the previous allocation system.

Given the uncertainty and controversy generated by the initial report of Liou, a conference entitled "International Perspective on Lung Transplantation: Adult and Pediatric Outcomes" was convened in June of 2008, bringing together different members of the pediatric and adult lung transplant community, experts in biostatistics, clinical research techniques, quality of life, and advocates of the CF community. The aim of this meeting was to understand whether transplantation resulted in a net benefit to patients. Our discussion of benefit extended beyond the simple length of survival. We began with an overview of survival and survival analysis and continued with considerations of evolving surgical methodology, peritransplant morbidities, pre- and post-transplant quality of life, the effects of patient adherence to therapy, and the burden of care. We included wide-ranging discussions of the impact on end-of-life care for $\mathrm{CF}$ and the culture surrounding lung transplantation. The participants identified additional areas of importance: the adequacy of current methods to measure quality of life, the difficulties associated with measuring patient adherence, the differences in selection of candidates for listing and allocation of organs between the United States and the United Kingdom, and the significance of variability in pre- and post-transplantation therapies among centers. After an animated discussion on the appropriateness of a randomized controlled trial, we sought consensus on goals and methods for further study. This roundtable discussion presents our sometimes opposing opinions and a series of new questions and expresses our collective determination to improve outcomes for all of our patients contemplating lung transplantation for $\mathrm{CF}$.

\section{Pediatric Lung Transplantation for Cystic Fibrosis: Overview and Historical Perspective}

\section{Stuart C. Sweet}

Lung transplantation for $\mathrm{CF}$ was first performed using a combined heart-lung transplant in 1983 (9), with the first bilateral lung transplants for CF performed a few years later (10). Shortterm success with lung transplantation prompted growth in the use of the procedure for $\mathrm{CF}$ and fostered hope in children and adults whose CF lung disease had progressed to end stage. Each year, approximately 200 patients with $\mathrm{CF}$, including approximately 25 children, undergo lung transplantation in the United States (www.optn.org; accessed 5/1/2009).

As with other solid organs, there are more candidates than available donors. Moreover, lung transplant is not a cure for CF lung disease; the median survival for adults after lung transplantation is only 6.4 years (11). Therefore, choosing the time to list a patient with $\mathrm{CF}$ for a lung transplant requires addressing two sets of issues: the first relates to ensuring that listing occurs early enough for the patient to survive the length of time needed to wait for organs (12); the second relates to ensuring that the transplant procedure provides "benefit," usually measured in terms of survival.

Reports intended to provide guidance to physicians and surgeons regarding the timing of listing began to appear in the early 1980s. One of the first and most widely referenced reports is from the Toronto Lung Transplant Program (13). This article attempted to identify patients with a risk of death greater than $50 \%$ at 2 years (based on the estimated waiting time for transplant at the Toronto center). The authors found that in the Toronto experience, patients with a forced expiratory volume in one second $\left(\mathrm{FEV}_{1}\right)$ of $20 \%$ of predicted had a $70 \%$ chance of death within 2 years, but the chance of death halved for every 10 percentage-point increase in $\mathrm{FEV}_{1}$. The authors concluded that "[p]atients with cystic fibrosis should be considered candidates for lung transplantation when the $\mathrm{FEV}_{1}$ falls below 30 percent of the predicted value. Female patients and younger patients may need to be considered for transplantation at an earlier stage."

Subsequent studies have attempted to refine those criteria. Robinson (14) suggested that for children, "consideration of lung transplantation referral should begin when young CF patients have a best $\mathrm{FEV}_{1}<50 \%$ predicted despite aggressive conventional treatment." Liou and colleagues (15) used data from the Cystic Fibrosis Foundation Patient Registry (CFFPR) and multivariate logistic regression methods to create a 5-year survivorship model. Significant factors in that model are referenced in Table 1. They suggested that patients with a 5-year predicted survival less than $30 \%$ be considered for transplantation, whereas patients with a predicted survival greater than $50 \%$ be excluded. They found no effect of considering rate of decline in lung function.

Using the CFFPR and multivariate logistic regression, Meyer-Hamblett and colleagues identified similar risk factors to those of Liou and colleagues as predictors of 2-year mortality (16). However, they found that their model was no better than the "FEV ${ }_{1}$ less than $30 \%$ " criteria as a predictor. Although both had high negative predictive value (98 and $97 \%$ ) each had only modest positive predictive value (33 and $28 \%$ ). The authors concluded that "transplant referral decisions based either on a multivariate logistic model or on the criterion of an $\mathrm{FEV}_{1}$ of less than $30 \%$ predicted are likely to result in high rates of premature referral. Better clinical predictors of short-term 
mortality among patients with CF are needed." A group from Washington University took a different approach, evaluating risk factors for rapid decline in $\mathrm{FEV}_{1}$ in patients at a single center (17) and finding younger patients and patients with malnutrition at increased risk. They concluded that "patients with CF should be referred for transplantation at a time when based on their rate of decline in lung function, the expected time for their percent predicted $\mathrm{FEV}_{1}$ to reach $20 \%$ equals the average local waiting time for donor lungs, or when the baseline percent predicted $\mathrm{FEV}_{1}$ reaches $30 \%$, whichever comes first."

Finally, a retrospective cohort study of 343 patients listed for lung transplantation at four academic medical centers was used to generate a multivariate model of waiting list mortality (18). Patients referred from an accredited cystic fibrosis center (hazard ratio [HR], 0.5; 95\% confidence interval [CI], 0.31.0), or listed after 1996 (HR, 0.4; 95\% CI, 0.2-0.7) were at lower risk. Patients with $\mathrm{FEV}_{1}$ of $30 \%$ predicted or less (HR, 6.8; 95\% CI, 2.4-19.3), $\mathrm{PaCO}_{2} 50 \mathrm{mmHg}$ or greater (HR, 6.9; $95 \%$ CI, 1.5-32.1), or who received nutritional intervention (HR, 2.3; 95\% CI, 1.3-4.1) were at higher risk. The authors concluded that "on the basis of these data, the presence of hypercapnia in the setting of better lung function and the requirement for nutritional interventions are additional factors that should be considered in developing future models to be used in allocating organs to the CF population" (18).

Thus, in spite of such studies, prediction of the appropriate time to offer transplant for CF remains largely subjective. This concept is reinforced in a recent update of guidelines for the selection of lung transplant candidates: "The decision of transplantation will eventually derive from a comprehensive evaluation that must take into account several indicators of disease severity such as $\mathrm{FEV}_{1}$, increases in oxygen need, hypercapnia, need for noninvasive ventilation, functional status (e.g., 6-MWD), and pulmonary hypertension" (19).

Whether this subjective process leads to timely listing and yields survival benefit from transplant for children with $\mathrm{CF}$ has been a matter for debate. A report from Great Britain (7) involving 124 children with cystic fibrosis who were accepted for lung transplantation between 1988 and 1998 suggests that lung transplant can provide survival benefit to children with $\mathrm{CF}$. In a multivariate proportional hazards model with transplant as a time-dependent covariate, the HR for transplant was 0.31 , suggesting a nearly $70 \%$ decrease in mortality risk after transplant. In contrast, Liou and colleagues used similar methodology to evaluate the benefit of lung transplantation for children

TABLE 1. CLINICAL RISK FACTORS FOR DEATH IN CF PATIENTS

\begin{tabular}{|c|c|}
\hline General CF Population & Patients with CF Listed for Transplant \\
\hline $\begin{array}{l}\text { Pulmonary function* and } \\
\text { exercise capacity }{ }^{\dagger}\end{array}$ & $\begin{array}{l}\text { Yearly rate of decline in percent } \\
\text { predicted } \mathrm{FEV}_{1}\end{array}$ \\
\hline $\begin{array}{l}\text { Microbiology (i.e., S. aureus, } \\
\text { B. cepacia) }\end{array}$ & Walk test results (distance ${ }^{\dagger}, \mathrm{Sa}_{\mathrm{O}_{2}}$ ) \\
\hline Nutritional status (weight)*† & Resting heart rate/hemoglobin \\
\hline Age $^{* \dagger}$ & Presence of pulmonary hypertension ${ }^{\dagger}$ \\
\hline Female sex* & Presence of diabetes mellitus ${ }^{* \dagger}$ \\
\hline Pancreatic insufficiency* & Albumin/nutritional intervention \\
\hline $\mathrm{CFRDM}^{\dagger}$ & Shorter height \\
\hline Lower socioeconomic status & $\mathrm{PCO}_{2}^{\dagger}$ and $\mathrm{PO}_{2}$ \\
\hline Pulmonary hypertension ${ }^{\dagger}$ & Listing year \\
\hline \multicolumn{2}{|l|}{ Number of acute exacerbations* } \\
\hline \multicolumn{2}{|l|}{ Geographic location } \\
\hline Care in CF center & \\
\hline
\end{tabular}

Definition of abbreviations: $\mathrm{CF}=$ cystic fibrosis; CFRDM = CF-related diabetes mellitus; LAS = lung allocation score.

Adapted from Belkin and colleagues (18).

* Included in 5-year survivorship model (15).

${ }^{\dagger}$ Included in LAS pre-transplant model (20). with CF in the United States (2). They reviewed data from 514 patients obtained from the CFFPR and Organ Procurement and Transplantation Network registries who were listed between 1992 and 2002 (248 patients from this group underwent lung transplantation). The authors implied that, if the patients in the cohort were to receive transplant with the clinical characteristics reported at the time of listing, only five patients would have a statistically significant likelihood of a survival benefit. Although the conclusions and implications of the Liou study have been challenged (4), taken together, the two studies suggest that in a system where patients are offered transplant in order of subjective urgency (as in the UK system) (7), the likelihood of survival benefit is higher than in a system with multiple centers, limited objective listing and transplant criteria, and allocation based on waiting time (as in the US) (2). The possibility that variability in transplant criteria between centers can account for some of the observations in the Liou study is reinforced by the observation that the introduction of an allocation system in the United States, based on estimates of transplant benefit and waiting list mortality (20), suggests a survival benefit for the majority: nearly $70 \%$ of adolescents with CF who were transplanted in the 2 years following the initiation of the new system were predicted to have a survival benefit at 3 years (Leah Edwards, UNOS, personal communication). If this prediction can be confirmed, it would strengthen the argument that transplant can provide survival benefit to children with $\mathrm{CF}$.

In their concluding remarks, Liou and colleagues (2) questioned whether a randomized, controlled trial of lung transplantation is warranted for children with CF. Such a study would be ethically and logistically challenging. Moreover, it would primarily be testing the efficacy of the process by which patients with $\mathrm{CF}$ were determined to be appropriate transplant candidates. And perhaps most importantly, it would not take into account the fact that the benefit of transplantation is not restricted to survival-improvement in quality of life is an equally important consideration for most patients.

A more realistic prospective trial would seek to identify the factors critical to predicting when offering transplant would maximize survival and quality of life benefit. Because of the number of centers performing pediatric lung transplantation in the United States, such a study would be logistically challenging and would be at risk for variability and bias. Minimizing such bias would require uniform pre- and post-transplant treatment protocols as well as uniform listing, transplant, and donor acceptance criteria (this step might in and of itself lead to improved survival benefit). Nonetheless, a prospective study that assesses biomarkers (i.e., inflammatory markers), considers genetic information in addition to the previously identified clinical risk factors, and measures quality of life and cost, in addition to survival benefit, would provide the best possible care to children with endstage lung disease due to $\mathrm{CF}$ and make the most efficient use of limited resources available for transplantation.

\section{Operative and Perioperative Considerations in Lung Transplantation}

\section{Samuel Brown and Mark L. Barr}

Outcomes after lung transplantation depend on many complex, interrelated factors, including donor status, graft surgical technique and preservation, the recipient's preoperative condition, transplantation surgical technique and postoperative care, and the effects of long-term immune suppression and comorbid illnesses. 
Although dramatic improvement has been made, further gains remain possible. In this section we review operative and perioperative aspects of the management of lung transplantation.

Causes of death in the immediate postoperative period (up to $30 \mathrm{~d}$ ), differ substantially from those later in the course of transplant. The most important causes of perioperative mortality are, in order of frequency, primary graft dysfunction, nonCMV infection, cardiovascular failure, and acute rejection (11). Operative contributions to these outcomes include donor and graft management, surgical implantation, reperfusion, and the more recently recognized importance of surgical control of gastro-esophageal reflux disease (GERD).

The quality of the graft plays an important role. Issues relevant to the donor include the surgical explantation and preservation technique $(21,22)$, donor physiological and demographic parameters (e.g., standard versus extended criteria), and the use of lungprotective ventilation (23-25), among others. Even the method of preserving the graft for transport is relevant. The addition of a retrograde flush to improve cooling and more uniform removal of inflammatory debris and embolic material from explanted lungs has been shown to improve performance of the graft after transplantation. Retrograde flush also appears to assure better distribution of flush solution and less severe impairment of surfactant function (26-28).

Once a healthy graft has been explanted and transported it must be successfully implanted. Several issues may affect early outcomes, including the recipient's underlying disease, duration of cardiopulmonary bypass (if used) (29-31), size discrepancies at the site of anastomosis, and technique for initiating reperfusion. Complications that may be encountered during transplantation include inadequate intrathoracic exposure, intraoperative hypotension, poor hemostasis, compromised anastomosis, inadequate graft function, dynamic pulmonary hypertension, or metabolic and/or respiratory acidosis $(32,33)$.

The physical and anatomical state of the thorax of the recipient plays an important role. Although children with cystic fibrosis have generally not undergone various thoracic surgeries associated with transplantation in older patients or other conditions, their pleural spaces are often severely distorted by recurrent bacterial infection. Patients who have experienced pneumothoraces may also have undergone pleurodesis, which increases the technical challenge but not the risk of poor outcome from transplantation (29).

Cardiopulmonary bypass may be used during lung transplantation on an elective basis, such as for very small body size or preexisting pulmonary hypertension; or it may need to be used on an emergent basis for refractory hypercapnia, dynamic pulmonary hypertension, technical complications, inadequate graft function, or poor exposure (30). Although data from the cardiac surgical literature does suggest an inflammatory effect from cardiopulmonary bypass, there is no evidence to suggest that bypass should be delayed when it is clearly indicated during transplantation $(30,34-39)$.

Primary graft dysfunction (PGD) is perhaps the most important problem postoperatively $(32,40-43)$. Injuries to the graft can result from the physiological effects of brain death in the donor, ischemia related to harvest, preservation, and transport, and reperfusion injury at the time of implantation $(27,44$ 46). Data from the University of Toronto have suggested that increased inflammatory cytokines in the graft at the time of harvest predicts PGD and death in recipients (21, 47, 48). Efforts are underway to clarify how best to predict PGD on the basis of donor status before or at the time of explantation.

PGD generally occurs within 24 hours. The clinical picture is similar to acute respiratory distress syndrome and is characterized by severe impairments of oxygenation, diffuse alveolar infiltrates, and low pulmonary compliance (32). Pathologically, the graft exhibits diffuse alveolar damage. PGD results in prolonged ventilator dependence, ICU and hospital stay, increased resource use, and increased mortality. The differential diagnosis of PGD includes hyperacute rejection, early infection, venous anastomotic obstruction, left ventricular failure, and hypervolemia with preserved cardiac function. A variety of surgical complications can contribute to or mimic PGD, including venous obstruction, arterial stenosis, malorientation of the graft, phrenic nerve injury, and size mismatch between graft and recipient. Donor factors also contribute to PGD including the inflammatory state $(45,49)$, endocrine failure, and hemodynamic instability associated with brain death $(45,49)$, as well as ventilator-associated injury $(35,23-25)$ from ventilator trauma or bacterial overgrowth of the graft. The age of the donor also has a significant effect on the deleterious effect of prolonged ischemic time, a point first demonstrated by Novick and coauthors (44). The method for reperfusion may also affect PGD $(40,46)$. Options to decrease reperfusion injury include the removal of leukocytes, modification of the reperfusate, adjustment of duration of reperfusion, and an adjustment of the pressure driving reperfusion.

The options for treatment of PGD include supportive care (i.e., lung-protective ventilation, negative fluid balance, and possibly pulmonary vasodilator therapy) (50). Several retrospective series have supported the use of extracorporeal membrane oxygenation as salvage therapy during acute PGD, although outcomes remain poor (51). In the event of a catastrophic PGD, urgent retransplantation has also been undertaken but should be considered extremely high risk (52-54).

In the early postoperative period, the balance between immune suppression and infection is critical. This is a matter of considerable therapeutic and prophylactic variability among transplant centers. A variety of factors predispose to development of serious bacterial or fungal infections after transplant (55, 56), including PGD, cytomegalovirus infection $(57,58)$, multiple transfusions $(30,32)$, colonization with multiresistant organisms before transplant (59-62), enhanced or extensive immune suppression, renal failure, or episodes of acute rejection. Unfortunately, as therapeutic options for viral infection have improved, fungal organisms predominate, with an incidence of 15 to $35 \%(56,63)$. Although aspergillus and candida are most common (and the risk of death in patients remaining intubated after transplant for prolonged periods may be related to increased invasive aspergillosis), cryptococcus, molds, and endemic mycoses all play a role in post-transplant fungal infection $(56,63)$. Several features unique to lung transplantation determine the predominance of fungal colonization and infection. Perhaps the most important factor is that the graft communicates directly with the outside environment. In addition, mucociliary clearance is impaired $(64,65)$, and bronchial blood supply to the anastomosis is disrupted (66). This causes chronic mild ischemia, which places the graft at particular risk for infection.

Rejection stands opposite to infection in the delicate balance of post-transplantation care; acute rejection increases the risk of chronic rejection, primarily manifested as obliterating bronchiolitis (OB). Investigators have documented a high prevalence of GERD in patients listed for transplant as well as in patients after transplantation (67). There is an increased rate of acute and chronic rejection in patients with GERD. One group assayed bile acids in bronchoalveolar lavage as a marker of significant reflux, documenting bile acids in perhaps $20 \%$ of transplant recipients, a finding associated with increased neutrophils and the chemokine IL-8, as well as a clear progression to OB (68). Case reports have documented significant improve- 
ment in lung function after fundoplication surgery, and uncontrolled series have supported this finding (69-71).

Managing the many factors determining early outcome in lung transplantation requires extensive experience and coordination. As with many other surgical or complex medical procedures, there is at least early evidence that mortality outcomes are improved at higher volume centers (72). The steady improvement in survival after transplantation over the course of the last decade suggests that increased experience with this complicated therapy improves outcome (11).

Although transplantation has achieved results once thought impossible, there is substantial opportunity for progress. Improved outcomes will result from advances in prevention of primary graft dysfunction, reduction of both acute and chronic rejection, and improved prevention and management of fungal and viral infections. These improvements will require careful coordination and collaboration between patients and physicians, between researchers and clinicians, and among different centers providing transplantation for patients with life-threatening pulmonary failure.

\section{(Non)-Adherence in Cystic Fibrosis and Lung Transplantation}

\section{G. D. Nossent, O. H. Bosma, E. A. M. Verschuuren, K. Vermeulen, E. J. L. E. Vrijlandt, and W. van der Bij}

Adherence is the extent to which the patient's behavior (taking medications, following a recommended diet, or executing lifestyle changes) matches the prescriber's recommendations (73). The term adherence is preferred above compliance, because compliance does not involve patient agreement with prescribed recommendations. Confusion over terminology still exists, and compliance and adherence are commonly interchanged casually.

Noncompliance or nonadherence to medical regimens is quite common. Nonadherence in children and/or in adults with CF is estimated to be between 30 and $70 \%$ for some aspects of treatment (74-76). Recently, a study of lung transplantation in children with $\mathrm{CF}$ failed to find systematic survival benefit in the United States (2). Nonadherence was not considered in that study, but it may play a role in the potential lack of survival benefit of lung transplantation in children (77-81).

\section{Nonadherence}

Transplantation, life-saving as it may be, leads to a chronic condition, sometimes called transplantation disease, which requires lifelong medical follow-up because of the risk of complications and deterioration of condition. Post-transplant patients must establish and maintain a rigorous daily routine in taking and precisely timing medications. Self-management includes monitoring parameters and symptoms, smoking avoidance and cessation, diet, exercise, alcohol restrictions, and sun protection.

A meta-analysis reviewed nonadherence in 147 studies of solid organ transplantation (77). Average nonadherence rates were calculated for 10 areas of the medical regimen. Key findings were reassuring. During any given year most transplant recipients are adherent $(77,79)$. Over time, nonadherence increases, and a sizable proportion of recipients ultimately become nonadherent (79). Reported nonadherence varies from 1 to $10 \%$ of patients after transplantation for substance use (tobacco, alcohol, illicit drugs) to 19 to $25 \%$ for nonadherence to immunosuppressants (79). Nonadherence rates varied substantially depending on the type of organ transplanted (78). Nonadherence for immunosup- pressants was highest in kidney recipients (77). Psychosocial characteristics like demographics, social support, and perceived health showed little correlation with nonadherence. Pretransplant substance use predicted post-transplant use.

\section{Nonadherence to Immunosuppressive Therapy}

Immunosuppressive therapy is crucial in preventing rejection and subsequent poor graft and patient survival after transplantation. Nonadherence with cyclosporine dosing correlates well with late acute rejection in heart transplant recipients (82). Usually immunosuppressive therapy consists of a combination of at least two or more immunosuppressants, usually including corticosteroids, which are uniformly disliked by patients. Few studies on nonadherence have concentrated on combination therapy. Relating nonadherence to medication requires consideration of various dimensions of behavior and raises difficult questions $(77-79,83,84)$. Is nonadherence total or partial? Is taking 80 or $90 \%$ of prescribed medication sufficiently adherent? Is it a problem of taking or timing? How should "drug holidays" initiated by patients with or without clinician approval be considered? Is there a difference in effect between nonadherence in the first year after transplantation and after 10 years?

Medication errors in a complex drug regimen after lung transplantation were described as important components of nonadherence (83). Patients were noted to err in recording changes in medication plans, changing out medications from pill dispensers, or never properly filling their pill dispensers. Clinicians were noted to dispense incorrect drugs (83). These errors were highly correlated with adverse clinical events.

The impact of nonadherence to other areas of the medical regimen (for example, diet, exercise, and lifestyle) has been investigated as a potentially important cause of poor outcomes, but no firm relationship has been established. Other factors that potentially influence nonadherence after lung transplantation, such as patient-doctor relationship, mood fluctuations or depression, and negative attitudes and misperceptions regarding medication have not been thoroughly studied $(77,78,85)$.

\section{CF and Nonadherence}

Treatment regimens that include improved antibiotics and use, nutritional support and exercise have considerably increased projected median survival in CF to more than 35 years (86-89). However, treatment remains complex and time-consuming, often interfering with activities of daily living (90-92). Adherence is superior to medication perceived as more important or more likely to improve quality of life $(74,93)$. Therefore, it is not surprising that adherence to digestive and respiratory medications is much better than the adherence to physiotherapy or nutritional supplements. Age and severity of disease have both negative and positive effects on adherence $(74,93)$. Living with $\mathrm{CF}$ appears to have a greater emotional impact on adolescent girls than boys (75). Such gender differences may contribute to differing levels of nonadherence and subsequently poorer outcome for adolescent girls (87, 94-96). Because of its incidence and prevalence, nonadherence with routine pretransplantation treatments must be considered as a potential risk factor for nonadherence after lung transplantation in $\mathrm{CF}$.

\section{Lung Transplantation, CF, and Nonadherence}

Survival benefit from lung transplantation in children with $\mathrm{CF}$ is compromised by diverse post-transplant medical complications. Graft dysfunction and bronchiolitis obliterans are as frequent in children as in adults. However, in children, a higher incidence of post-transplant lympho-proliferative disorder, growth retardation, surgical complications, and respiratory tract infections are reported (80). 
The combination of relatively small numbers of children transplanted annually (worldwide, 50-60 patients) (1) and considerable age differences (from 1 to $18 \mathrm{y}$ ) complicate precise analysis. Nonadherence per se has not been implicated as a factor for poor outcome primarily due to lack of investigation. Thus, efforts to improve survival after lung transplantation should include exploration of the potential impacts of nonadherence and practice improvement to eliminate known negative causes and effects $(2,77,80,97)$. First, to facilitate study, nonadherence must be defined more precisely in all domains of the medical and psychosocial regimen. Second, institutional strategies to minimize medication errors and misperceptions about medications must be implemented and monitored. Third, compliance taking medication with proper timing for more than 80 or $90 \%$ of prescribed doses is arbitrarily considered adherent. Routine monitoring to determine whether patients reach this level of adherence can be accomplished by measuring medication levels in blood and by using electronic monitors incorporated in medication dispensers.

Finally, the interaction between patient-perceived outcomes and many aspects of nonadherence may be systematically investigated and routinely followed. Both the tendency to adhere to therapy due to perceived quality of life and the impact of adherence on quality of life may be measured and tracked, probably best and relatively simply by using validated healthrelated quality of life (HRQoL) questionnaires such as the SF 36 (98-100) or the CF Questionnaire-Revised (CFQ-R) (101). Measurements obtained using such tools will likely lead to increased insight into underlying reasons for nonadherence and may suggest possible interventions to reduce nonadherence and its potential negative effects on survival.

\section{The Importance of Measuring Health-Related Quality of Life}

\section{Alexandra L. Quittner, David H. Barker, Laura S. Blackwell, Sandy L. Romero, and Marlyn S. Woo}

Over the past two decades, advances in surgical techniques and immunosuppressive medications have increased the use of lung transplantation for patients with end-stage pulmonary disease, becoming a standard of care for patients with CF (1). Although the primary indication for lung transplantation in adults is chronic obstructive pulmonary disease (COPD), $\mathrm{CF}$ is the primary indication for pediatric patients $(<18 \mathrm{yrs})(102)$. According to a recent pediatric registry report from the International Society for Heart and Lung Transplant (ISHLT), 1,155 pediatric lung transplants for children with CF were performed from 1984 through June, 2007 (1). Despite significant improvements in immunosuppressant agents, a recent study indicated that there has been little to no increase in survival among pediatric patients with $\mathrm{CF}$ after lung transplantation compared with waitlist controls (2). Although lung transplantation may not increase life span, it may improve HRQoL in transplant recipients (2). To address this question, studies of lung transplantation in CF should include reliable and valid measures of HRQoL.

Measures of HRQoL have been used extensively in adult lung transplant recipients, with most studies demonstrating immediate and sustained benefits following transplant (103109). In general, reports of HRQoL in adult lung transplant recipients are favorable, with a majority of patients reporting satisfaction with their decision. For many patients, gains in HRQoL outweighed potential reductions in longevity (110).
However, these studies used a variety of measurement tools which focused on different dimensions of HRQoL, making it difficult to compare across studies. Future research should utilize a more standardized approach to assessing HRQoL (111).

In contrast to the adult population, little research on HRQoL has been conducted with pediatric lung transplant populations, and none has been published on children with $\mathrm{CF}$. In the only two published studies of quality of life and health outcomes following transplantation, some evidence for improvement has been found. In an older study, Wray and colleagues used patient and parent semistructured interviews, rather than a validated HRQoL measure, to assess outcomes from pre- to posttransplant (112). Their results indicated significant improvements in perceptions of HRQoL immediately following transplant; however, they did not follow these patients longitudinally to see if these benefits were maintained. More recently, Liou and colleagues examined important health outcomes of pediatric transplantation, such as days in hospital, number of complications, and incidence of bronchiolitis obliterans (2). This study found a decrease in hospitalizations, but an increase in complications after transplantation, making it difficult to draw conclusions about the HRQoL benefits of transplantation for pediatric patients with CF. Neither of these studies used a standardized measure of HRQoL and therefore could not evaluate the potential benefits of transplantation on domains, such as physical, emotional, and daily functioning. Given the paucity of data on HRQoL outcomes in pediatric lung transplantation in $\mathrm{CF}$, we conclude that there is an urgent need for multisite, longitudinal studies of the effects of transplantation in CF using reliable, valid, and disease-specific measures.

Measurement of HRQoL in specific medical populations has increased in sophistication over the past 20 years, recently highlighted by release of a draft Guidance by the Food and Drug Administration in the United States on HRQoL and other types of patient-reported outcomes. This guidance outlines a set of rigorous requirements for instruments used to assess the efficacy of new treatments and interventions while also encouraging their use as a means of representing the patient's perception of benefit $(101,113-117)$. It is critically important to answer the question about the extent to which lung transplantation for CF provides a significant HRQoL benefit (118). There is now a reliable, valid, and widely used HRQoL measure for $\mathrm{CF}$, the CFQ-R, which has demonstrated responsivity across a variety of clinical trials $(114,116,118)$. The Cystic Fibrosis Foundation recently funded a longitudinal study using the CFQ$\mathrm{R}$ in pediatric patients receiving lung transplants, yielding some promising results $(119,120)$.

Several challenges should be considered when including a measure of HRQoL in studies of pediatric lung transplantation, including the need to use a context-specific measure that is sensitive to the issues of patients with $\mathrm{CF}$ and one that reflects the developmental changes that occur in children and adolescents $(111,117)$. Complex methodological issues must also be addressed, including the use of longitudinal assessments of HRQoL prior to and following transplantation (including longterm follow-up), sample sizes large enough to use complex, longitudinal analytical techniques (e.g., longitudinal modeling to account for nonrandom missing data) (121), methods to accommodate the variability observed in self-reported HRQoL, and the disentangling of survival from HRQoL benefits (e.g., use of quality of life and quality-adjusted survival, Q-TWIST) (122). These methodological issues have severely limited our ability to measure the potential quality of life benefits of pediatric lung transplantation.

To address these challenges, a prospective study assessing $\mathrm{HRQoL}$ in pediatric CF lung transplant candidates is in process. 
This 3-year study includes a large sample of patients from 12 centers belonging to the International Pediatric Lung Transplant Collaborative. The study design includes assessments of HRQoL at multiple time points pre- and post-transplant, using the age-appropriate versions of the CFQ-R. Preliminary results indicate that following transplantation, children, and adolescents reported significant improvements on the CFQ-R Respiratory, Physical, Health, Social, Eating, and Treatment Burden scales. Similarly, parent-reported CFQ-R scores showed substantial improvement on all CFQ-R scales. Although these results are promising, we also observed decreases in these benefits by about two years post-transplantation, which was related to adverse events, such as bronchiolitis obliterans (123). To date, however, the Q-TWIST methodology has not been applied to these data, and the final analyses have not been completed. These preliminary findings may shed light on the crucial question of whether pediatric lung transplantation for children and adolescents with CF is beneficial, independent of survival. It may also provide valuable information for families and health care teams who are deciding whether or not to pursue transplantation. Despite its potential, the small sample size for this study may preclude a definitive conclusion. A future study with a larger sample size and more systematic data collection is needed.

\section{Three Sociohistorical Challenges to Improving Lung Transplantation for Cystic Fibrosis}

\section{Walter M. Robinson}

Efforts to improve the system of lung transplantation for cystic fibrosis can be understood better by examining three intersecting socio-historical themes: the changing survival patterns for cystic fibrosis, the role of research in evaluating solid organ transplantation, and the tension between local and centralized control of organ transplantation in the United States.

\section{The Availability of Lung Transplantation Disrupts the Expected Trajectory of Cystic Fibrosis for Children and Adults, Making Decisions about Transplantation More Difficult}

As they grew up, few adults with $\mathrm{CF}$ who are alive today expected the possibility of lung transplantation. Instead, they had a clear set of expectations about survival, often focusing on what some have called "the magic age of 30," many adults have made decisions in life predicated on limited survival and on a certain pattern of manageable but irreversible decline in health (124). The advent of transplantation as a rescue from respiratory failure altered these expectations. In interviews from the Project on Adult Care in CF (125), many adults expressed surprise that they had survived as long as they had, and many viewed transplantation and the possibility of rescue from the expected trajectory, as deeply unsettling. Many were aware that the possibility of transplantation would lead them to make substantial changes in previous patterns of self-management and clinical care as well as family and work life. Adding to the sense of disruption was the need to make a new type of medical decision, one that offered the uncertainty of either unexpected survival or premature death (126).

The situation for children and adolescents differs in direction but not in character. As CF survival has increased, it has become far less common for children with $\mathrm{CF}$ to develop severe lung disease during childhood and adolescence. Those children and teenagers who do have severe lung disease experience a parallel sense of disrupted expectation (127). As with adults, the difficulty of making a decision with life-saving or life-shortening possibilities is amplified by the unexpected trajectory of the disease.

\section{The Adoption, Evaluation, and Improvement of Invasive, Irreversible Surgical Techniques Has Proceeded Along a Distinct Trajectory in the United States}

The adoption of new invasive surgical techniques generally proceeds along a different trajectory than new medical therapies (128). Expectations of research design and testing are substantially different when the therapy is irreversible, highly invasive, and applied to a patient population for whom options are seen as limited. Lung transplantation for CF is not an exception. The procedure was developed not through a series of deliberately designed randomized trials, but rather through a decentralized process of continuous innovation, reasoning by analogy, single-number experimentation, and adaptation to patient variation (129). It is fair to say that transplantation for end-stage CF lung disease has not yet emerged from this period of decentralized innovation and evaluation. The small number of lung transplants performed for $\mathrm{CF}$, and the relatively large number of centers where these procedures are performed in the United States (in contrast to the United Kingdom and Canada) make systematic evaluation and improvement of $\mathrm{CF}$ lung transplantation even more difficult.

Studies of efficacy in organ transplantation are less likely to be randomized at the early stages of the procedure, and few studies can be performed reliably for factors such as patient selection in this stage. Much of the clinical data will have to be gathered using historical controls (130). As procedures mature, there is likely to be increasing use of randomized trials, but before this occurs, there is usually a protracted period of change during which variations in practice and outcome are common, and interpretation of outcomes should be done with careful attention to these variations. The specific details of the procedure, the decentralized locations where it is performed, and the desperate straits of the patient population on whom it is performed mean that any study must be both carefully designed and undertaken at the right moment in the development of the therapy (131).

\section{In Spite of Revisions in National Policies to Manage Lung Transplantation, There Remain Substantial Challenges in Evaluating Lung Transplantation for Cystic Fibrosis which Arise from the U.S. System of Organ Allocation and Transplantation}

The national system for lung allocation was revised in 2005 (20). Some disagreement remains whether the new allocation system responds in the best way to serve the needs of those with CF. There are several factors inherent in the model of transplantation now applied in the United States that make evaluation of lung transplantation for CF challenging.

First, the demand for transplantable lungs is determined both by the nature of lung disease and by the policies of the waiting list. The allocation changes in 2005 revealed what many in the CF community already knew: that many patients were on the waiting list as a kind of insurance policy, rather than as a reflection of true need or disease severity. The demand for lungs was artificially inflated by the specifics of the waiting process, which overemphasized time on the list as a selection variable $(132,133)$. It may be true that this artificially inflated demand is useful in keeping pressure for improvement on systems for efficient organ donation and harvesting, but it may also be the case that the inflated demand skews our intuitions of the best way to organize lung transplantation for $\mathrm{CF}$. 
Second, waiting times for organs are a function not just of the listing system, but also of the decision to limit the judgment of the local clinician in allocating organs among those waiting at a given center. National systems can be structured so as to take into account expert clinician judgment, as was demonstrated during this meeting by descriptions of the British and Canadian systems $(7,134,135)$. It may well be the case, as some have argued, that outcomes for transplantation in the United States are determined to a large part by bureaucratic processes rather than variations in surgical or medical procedures.

Third, the decentralized nature of the United States organ transplantation process and the competition between medical centers for transplant revenue may be hampering collaborative evaluation and improvement of the outcomes of lung transplantation in children with CF (136). National reluctance to limit transplantation to a few expert centers may create barriers to improvement that are then amplified by the differences in insurance coverage, the small number of procedures overall, and variations in training and expertise (137). Some of these factors are unique to $\mathrm{CF}$ and the uncertainties of the organ supply, and thus are less easily improved; other barriers to improvement are more clearly manmade and could be tackled were there the will to make the necessary changes.

\section{Alternate Models of Selection for Lung Transplantation: What Distinguishes the British System?}

\section{Paul Aurora and Helen Spencer}

Although published survival figures following lung transplantation in children with CF are similar for the United Kingdom and the United States $(1,7)$, the calculated survival benefit appears markedly different $(2,7)$. This section of the Roundtable summarizes the transplant listing and organ allocation systems of the United Kingdom, which may have some impact upon the survival benefit from the procedure, and therefore may explain some of this discrepancy.

Lung transplantation in children in the United Kingdom commenced in the early to mid-1980s. There are now two pediatric transplant centers in the country: Great Ormond Street Hospital in London and Freeman Hospital in Newcastle. At the time of writing, the Great Ormond Street center performs eight to ten pediatric lung transplantations per year, while the Newcastle center performs fewer than this with the numbers varying considerably from year to year. All core activity of the cardiothoracic transplant centers in the United Kingdom is funded directly from the central National Health Service budget, administered through the National Commissioning Group. This group regularly audits the performance of all transplant centers, and as part of this, they expect centers to work in co-operation rather than in competition with each other. Individual centers have the liberty to determine their own management protocols, but they meet regularly to share information and ensure common best practice. As of 2008, there is a national referral proforma for both adults and children.

The rules for organ allocation in the United Kingdom are reviewed regularly and minor changes are frequent. However, the general principles have remained constant. Each of the adult lung transplant centers (of which there are currently five) has its own retrieval zone. Any donor offers within that zone are allocated to the local transplant center initially and are then offered in rotation to the other transplant centers in the country if the local transplant center does not have a suitable recipient.
As the Great Ormond Street Hospital does not have its own zone, it is given a higher priority on the subsequent rotation. Organs from pediatric donors are offered in rotation between the Newcastle and Great Ormond Street centers. Once an organ is offered to a center, that center has considerable discretion in deciding which recipient to transplant. In pediatric practice, once blood group and size matching has been performed, there is often only one suitable recipient. If there is more than one possible recipient, then the Great Ormond Street policy has always been to transplant the sickest recipient irrespective of time spent on the waiting list. If the clinical conditions of the recipients are similar, then decision is made on the basis of waiting time. This practice has only ever been audited once, in 2000 (unpublished data). At that time, we could not find any evidence that sicker children were receiving transplants more quickly than those who were less unwell, but that may be because our tools for deciding which patients are sickest are still rather crude. For cardiac transplantation, a national system of urgent listing now exists that is centrally administered and takes priority over interregional and within-center policies for organ allocation. A similar system has been considered for organ allocation in lung transplantation but has not yet been implemented.

As a general principle, children in the United Kingdom are listed for transplantation as late as possible while considering the likely waiting time for a donor. In practice, this translates to children with CF only being considered for lung transplantation if they are already on full medical therapy, and despite that have a predicted life expectancy of 2 years or less without transplant. To our knowledge, most of our European colleagues apply similar guidelines for transplant listing. The benefit of this approach is that most children who undergo lung transplantation will have their lives extended as a result. The disadvantage is that by listing children fairly late in the course of their disease, there are inevitably some who will die before receiving organs. In common with most other transplant centers, we use a variety of clinical and physiological data to prognosticate in children referred to us in an attempt to identify the correct time of listing $(134,13,15)$. However, any such survival estimation is inexact in individuals, and occasionally children will die before even being listed. This is obviously an important consideration, and listing decisions are not taken lightly.

Our policies were last audited in detail almost 10 years ago, and these audits were published in a series of three papers. The first was designed to identify prognostic markers to determine which children have an expected survival of 2 years or less (134). Although the markers identified in the study are still used by us, we recognize that the treatment of CF has improved over the last 10 years, and our current decisions are adjusted accordingly, with children now being listed with poorer lung function and exercise test results than previously. The second of our published audits (7) was a similar study to that published by Liou and coworkers in 2008 (2). In this study we analyzed 124 children listed for transplantation during the first 10 years of our program and calculated a highly significant survival benefit associated with the procedure (partial hazard ratio for transplantation 0.31 [0.13-0.72]; $P=0.007)(7)$. It should be noted the predicted life expectancy without transplant for this cohort was approximately 1 year, and more than half the population died without undergoing transplantation. In the third related audit, we demonstrated that our transplant outcomes (survival) were not affected by how severe the child's CF lung disease was at the time of transplant (135). With this audit, it should be noted that we had a policy of not transplanting children who were ventilated, and it has been demonstrated that both adults and children who undergo lung transplantation while receiving invasive ventilation have a poorer outcome than other re- 
cipients (11). The London studies described above are now 10 years old and are likely to be outdated to some extent. They have not been repeated for the simple reason that the number of deaths on our waiting list is much lower than previously (due to a reduction in the number of pediatric referrals with $\mathrm{CF}$ ), and a repeat of this single center study is therefore likely to be underpowered. A recent survival analysis from the Zurich transplant center has circumvented this obstacle by calculating their recipients estimated survival without transplantation from a published prognostic model $(15,94)$, and comparing this with the post-transplant survival of those same recipients (138). This method (94) is open to many biases and the result should be interpreted with caution. However, we note that as with the earlier London study, the Zurich analysis calculates a significant survival benefit for their CF population with no adverse impact of pediatric age at transplantation.

In summary, we note that the survival study reported by Liou and colleagues (2) has a conclusion that is dramatically different from our earlier analysis from London (7). As the published post-transplant survival in both countries is similar, we suggest that a likely reason for the conflicting results relates to differences in the related issues of donor allocation and timing of listing, with UK patients listed much later. We also note that the situation in the United States has changed dramatically since Liou and colleagues' analysis. In 2002, the United Network on Organ Sharing introduced the lung allocation score (LAS) for allocation of lung organs to all patients aged 12 years or older (20). This score aims to allocate scarce organs to those patients who have the potential for greatest survival benefit (i.e., those who have the poorest predicted survival without transplant and the best predicted post-transplant survival). This system is described in greater detail elsewhere (20), but we observe that the LAS has the potential to incorporate the advantages of the UK listing model while minimizing the disadvantages.

\section{Some Comments on Study Design}

\section{R. Cox}

Most statistical work is concerned with the analysis of data, aiming to extract useful and reliable information and to present that information in a lucid way. There is another side to statistical thinking connected with the planning of studies. These may be cohort or case-control observational studies or intervention studies.

Ideas about the design of experiments probably go back several centuries, but the first systematic work on design in the presence of substantial haphazard variation was done 80 years ago in a broadly biological context with an initial focus on agricultural field trials. The principles were set out later by Fisher in 1935 in a book still in print (139). The first randomized clinical trials influenced by these ideas came also in the 1930s. Large-scale use of randomized clinical trials, especially in examining pharmaceutical products for safety and efficacy, is a feature of the last 30 years or so.

It is obvious, but has to be stated, that there is no formula, computer package, or book that can dictate how to design a study. Every field has its special constraints that may be ethical, physical, or economic. These have to be obeyed and this is nowhere more obvious and compelling than in the $\mathrm{CF}$ issues discussed in this meeting. There are, however, objectives that can be specified. Here they are essentially twofold, namely, the achievement of secure interpretation and of adequate sensitivity.
By security is meant that if we compare transplanted and nontransplanted patients with respect to their survival, quality of life, or other features of concern, and if we find a clear difference, then we can conclude that this is genuinely a consequence of transplantation. We need to be able to dismiss the possibility that the two groups of patients are distinctly different in some other relevant respect that makes direct comparison of their survival misleading. The second objective is recognizing the presence of substantial haphazard variation to achieve adequate precision or power as swiftly as possible.

How is security to be achieved? One route is by careful analysis. If the transplanted and nontransplanted groups have seriously different proportions of males and females, analysis can and indeed must adjust for that. Indeed, one may also examine whether any transplant effect is the same for the two genders, or what statisticians misleadingly call treatment by gender interaction. Analysis will and should deal with imbalance in well-recognized and recorded features. It will not deal in this way with unrecorded and maybe unrecognized features.

The second route to security is randomization and is aimed primarily at such unknown sources of systematic distortion. By randomization in the present context is meant the use of an impersonal device such as the toss of a fair coin, or equivalent, to determine the allocation of each individual. In principle at least, this ensures that, when compared, patients who are transplanted differ from those who are not transplanted only by the transplantation and by the play of chance. Rigorous probability calculations are possible about the latter.

An essential feature of randomization is that the insurance against bias is achieved publicly; it does not depend on the skill of the investigator in achieving balance. In fact, there is empirical evidence from many fields that achieving such balance by purposive selection is surprisingly difficult. A well-documented old but still instructive example is the Lanarkshire milk experiment (140), a large nutritional study in which an essentially randomized arrangement was "improved" to produce better balance. The improvement, however, introduced a bias focusing a nutritional supplement on disadvantaged children. This had a disastrous effect on interpretation. For a brief discussion and further general details about design, see Cox (especially p.77) (141). For a general account of clinical trials, see Piantadosi (142).

Randomization is a powerful tool but there are some clear difficulties. First, and most obviously, there may be extremely strong ethical difficulties or impracticalities of implementation that, in the shorter or longer term, may be overwhelming. Second, there is a certain counterintuitive element in sacrificing control over an aspect of a study into the lap of chance. The sacrifice is an insurance premium paid to achieve a certain kind of security. There are many contexts where the premium is effectively very small compared with the security achieved, but clearly each study has to be considered on its merits.

There are some more technical statistical advantages to randomization that are largely irrelevant here. The central point is that randomization is a tool and in many contexts a very powerful one, but if the tool cannot be used, the objective of achieving security of interpretation remains. If randomization cannot be used, careful analysis and appropriate data collection become all the more important. It is in some ways a pity if, in using the term "randomized controlled" trial, the emphasis is put on the first word rather than on the second!

It is a mistake to argue that if the allocation process (i.e., the choice of patient to be transplanted) is complicated and involves many apparently haphazard features, then randomization is not needed. Indeed, it is precisely in such cases that biases from unappreciated sources can arise. In some situations 
a feature such as $\mathrm{ABO}$ blood group might be equivalent to a randomizer but clearly there is a strong assumption involved in that.

A study design for assessing the effect of transplantation on survival, quality of life, and other outcomes that serves as a reference point for discussion but is clearly impracticable, is the following:

When a donor organ becomes available, if possible, find a matched pair of patients from the same region, equally suitable for transplantation. The matching could be on whatever criteria were judged suitable. Randomize one patient to transplantation and the other never to be transplanted. Follow patients and record quality of life scores, survival time, etc.

A modification of this that might be viable under some circumstances is that the patient of the pair not chosen would be top priority for transplantation at the next relevant occasion. In a simple situation this implies that half the patients are unaffected by the scheme, a quarter are transplanted earlier, and a quarter later. The statistical effectiveness of the scheme depends on a nontrivial proportion of the deferred patients not surviving to be transplanted. If that proportion is less than one-quarter, the procedure is probably not viable.

A final possibility is to form the pairs as above but to abandon the randomization, making an informed choice between the pair. If feasible, notes on the reason for the choice could be informative. There seem to be no ethical objections to such a design. There would be the burden of additional data collection.

In principle, any of the above procedures involving matching patients is available regardless of the criteria used to produce the matches. Different criteria could be used in different centers, although it might be informative to know what those criteria are.

There is, of course, much more to study design than the issues just discussed. In particular, the choice of what data to record, and the steps to ensure its reliability, are crucial. An assessment is also needed of the time required to accrue sufficient patients to achieve adequate precision. Particularly for pediatric lung transplantation, the accrual may be so slow that only an international study would be viable.

The above considerations are for an investigation intended to clarify the advantages and disadvantages of transplantation.
To study only transplanted patients with the objective of establishing predictors of their subsequent life-course would be simpler but would have no direct necessary connection with the effectiveness of the transplantation.

\section{Lung Transplantation and Cystic Fibrosis Lung Disease: Questions and Challenges}

\section{Marlyn S. Woo and Geoffrey Kurland}

Lung transplantation is an option for selected pediatric and adult patients with advanced or severe lung disease that has failed to respond to standard therapy. Despite the steady increase in the number of candidates listed for lung transplantation, there have been few population-based studies on the benefits (including survival) of lung transplantation for adults and children with end-stage lung disease $(7,143,144)$. Beginning in 2001, Liou and colleagues published a series of population-based studies on lung transplantation for patients with cystic fibrosis (CF) $(2,94,145)$ using the Cystic Fibrosis Foundation Patient Registry (89) and United Network for Organ Sharing data (146). Liou and colleagues found fewer CF lung transplant recipients with survival benefit than had been reported in earlier publications describing CF lung transplant recipients in single-center reports $(94,145)$ The findings of Liou and his coworkers elicited serious discussion within the lung transplant and cystic fibrosis communities (147-150). However, widespread controversy occurred after publication of the pediatric CF lung transplant data (4-6), which showed an especially poor survival benefit for these recipients compared to pediatric patients with $\mathrm{CF}$ who did not undergo lung transplant surgery $(2,4)$. The June 2008 Lansdowne Conference brought together a variety of medical professionals including pediatric and adult pulmonologists, transplant physicians, cardiothoracic surgeons, and statisticians. The aim was to discuss these issues with a goal of reaching a consensus on future directions in clinical research to lead to a more appropriate selection of pediatric lung transplant candidates, to improve post-transplant outcomes in these patients, and to better understand the explanations for dissimilar outcomes

TABLE 2. PATIENT, FAMILY OR CARETAKER, AND DONOR CONSIDERATIONS FOR LUNG TRANSPLANTATION IN CYSTIC FIBROSIS

\begin{tabular}{llc}
\hline Patient & \multicolumn{1}{c}{ Family or Caretaker } & Donor \\
\hline CF mortality risk & Socioeconomic status & Presence of inflammation \\
Inflammation & Single or dual caregivers & Donor Type \\
Endurance & Siblings: & Deceased \\
Sputum and lung infections & Healthy & Non-heart beating \\
Pulmonary function by spirometry & With CF or other chronic illness & Living lobar \\
Referral criteria & Education levels & Donor management methods \\
Gas exchange by blood gases & Perception of patient QOL & Organ \\
pH & Socialization & Preparation \\
Oxygenation & Preservation \\
Hypercarbia & & Ischemic time \\
Respiratory failure requiring mechanical support & & \\
Patient knowledge and education level & & \\
History of adherence & & \\
Socialization & & \\
Quality of life (QOL) & & \\
Psychiatric illness & & \\
Depression and pain & & \\
Psychosis & & \\
Health insurance & & \\
\hline
\end{tabular}


TABLE 3. SURGICAL AND IMMEDIATE POSTOPERATIVE CARE CONSIDERATIONS

Center specific practices

Induction

Immunosuppression levels

Cardiopulmonary bypass

Transplant surgeon and team experience

Intensive care unit support and experience

reported for pediatric $\mathrm{CF}$ lung transplant recipients from different centers.

At the conference onset, participants agreed that:

1. Optimal care for CF children and adults, whether before or after lung transplantation, should remain a primary goal

2. Lung transplantation should remain an option for selected patients with $\mathrm{CF}$ and advanced lung disease

3. Multiple factors influence the outcome of lung transplant recipients including:

a. physiological variables

b. patient-specific variables

c. lung transplant and CF Center-specific practices

d. infectious agents

4. There is a need for evidence-based practice guidelines for lung transplant centers

5. A prospective, multicenter study on patients with $\mathrm{CF}$ and lung transplant is necessary to answer important questions on criteria for candidate selection and transplant practice guidelines.

Before embarking on collaborative clinical research in the area of CF lung transplantation, there must be consistent terminology and procedures among lung transplant centers. In particular, there should be a definition of benefits from the procedure. Specifically, the attendees agreed that defining the "benefit" following lung transplantation by the length of survival is inadequate. Survival per se as a sole determinant does not address factors that are more difficult to quantify yet potentially quite important. Among these factors is patient quality of life. It was felt that improvement in quality of life, even if survival is suboptimal, may be important to a CF lung recipient. Other factors that could also be considered in determining the benefit of a lung transplant might include pulmonary function tests, physical endurance, functional status, arterial oxygenation, and need for supplemental oxygen.

Factors that affect outcome in lung transplant can be classified under the following headings: Lung Transplant $\mathrm{Pa}$ tient, Family or Caregiver, and Donor Characteristics (Table 2); Surgery and Postoperative Care (Table 3); Immunosuppression Regimen, Complications; and Clinical Follow-up (Table 4). Generally, individual risk factors do not correlate well with either post-transplant morbidity or mortality. There remains a need to determine which factors are most useful in directing changes in pre-transplant and post-transplant patient management to improve outcome. The consensus of Conference attendees was that without clinical factors clearly predictive of outcomes, a range of biomarkers and additional potential risk factors should be considered for further multicenter investigation $(35,37,38,45,46,49,68,71)$. For example, biomarkers of inflammation (IL-2; IL-6; IL-8; IL-10; TGF- $\beta$, etc.) in the sera or sputa of patients with $\mathrm{CF}$ awaiting transplant may better predict which patients are most likely to deteriorate more rapidly, providing impetus for earlier transplantation (151153). The same inflammatory biomarkers post-transplant may influence choices for immunsuppressive regimens, need for invasive studies such as bronchoalveolar lavage and transbronchial biopsy, or antimicrobial treatment. Unfortunately, no specific session was devoted to this discussion. Rather, short discussions arose during and around the various sessions, and it became apparent to the conference organizers that any future conference would do well to include biomarkers as a specific session topic.

Other factors for study include a uniform measure of $\mathrm{CF}$ quality of life, medical adherence, and patient and family socioeconomic status. These topics were more readily identified with a specific session as reflected above. However, further discussion is still needed to determine the optimal areas of clinical research.

The Lansdowne Conference participants agreed that longer duration of survival and improved quality of life are the goals of successful lung transplantation. Yet, the best practice to consistently achieve the highest survival and quality of life in CF lung transplant candidates is elusive. Nevertheless, the Conference attendees agreed that we can improve CF lung transplant outcomes. That improvement is likely to include improved

TABLE 4. POST-TRANSPLANT COURSE CONSIDERATIONS

\begin{tabular}{|c|c|c|}
\hline Immunosuppression Challenges & Complications & Patient Follow-up Issues \\
\hline $\begin{array}{l}\text { Optimizing immunosuppression } \\
\text { Chimerism } \\
\text { Over-immunosuppression } \\
\text { Idiosyncratic (genetic?) increased risk of rejection } \\
\text { Monitoring immunosuppression }\end{array}$ & $\begin{array}{l}\text { Rejection } \\
\text { Acute } \\
\text { Chronic } \\
\text { Acute on chronic } \\
\text { Infection } \\
\text { Bacterial } \\
\text { Burkholderia cepacia } \\
\text { Pseudomonas aeruginosa } \\
\text { Staphylococcus aureus (including MRSA) } \\
\text { Fungal } \\
\text { Aspergillus } \\
\text { Scedosperminum } \\
\text { Viral } \\
\text { Epstein-Barr } \\
\text { Cytomegalovirus } \\
\text { Hypertension } \\
\text { Renal insufficiency and failure } \\
\text { Diabetes } \\
\text { Malignancy }\end{array}$ & $\begin{array}{l}\text { Frequency_how much is enough? } \\
\text { Clinic location and team } \\
\text { Transplant } \\
\text { CF } \\
\text { Primary care } \\
\text { Post-traumatic stress disorder } \\
\text { Patients } \\
\text { Family and caregivers } \\
\text { Adherence } \\
\text { Detection } \\
\text { Intervention } \\
\text { Prevention } \\
\text { Continuing patient, caregiver, and family education }\end{array}$ \\
\hline
\end{tabular}


candidate selection criteria and optimized timing of referral for transplantation. After transplantation, improvements are likely to include standardized care, including induction and maintenance immunosuppression, antimicrobial treatment, patient rehabilitation, and graft surveillance. Lung transplantation remains a high risk procedure, however, it remains the only treatment option with the potential to ameliorate symptoms, preserve quality of life, and extend life for patients with advanced cystic fibrosis lung disease.

Conflict of Interest Statement: F.R.A. has received reimbursement from a noncommercial entity: NIH (more than $\$ 100,001)$. P.A. has received funding from noncommercial entities: Asthma UK (more than $\$ 100,001)$, and CF Trust (more than $\$ 100,001)$. He also has a financial relationship with Smiths Medical (more than $\$ 100,001)$. D.H.B. does not have a financial relationship with a commercial entity that has an interest in the subject of this manuscript. M.L.B. does not have a financial relationship with a commercial entity that has an interest in the subject of this manuscript. L.S.B. does not have a financial relationship with a commercial entity that has an interest in the subject of this manuscript. O.H.B. does not have a financial relationship with a commercial entity that has an interest in the subject of this manuscript. S.B. does not have a financial relationship with a commercial entity that has an interest in the subject of this manuscript. D.R.C. does not have a financial relationship with a commercial entity that has an interest in the subject of this manuscript. J.L.J. does not have a financial relationship with a commercial entity that has an interest in the subject of this manuscript. G.K. does not have a financial relationship with a commercial entity that has an interest in the subject of this manuscript. G.D.N. does not have a financial relationship with a commercial entity that has an interest in the subject of this manuscript. A.L.Q. has received reimbursement for consultancies with Gilead Sciences $(\$ 5,001-$ $\$ 10,000)$, Transave, Inc. $(\$ 1,001-\$ 5,000)$, and has also served on an advisory board for Genentech, Inc. $(\$ 1,001-\$ 5,000)$. She has also received honorarium for lectures $(\$ 1,001-\$ 5,000)$ and funding for research (more than $\$ 100,001$ ) with Novartis Pharmaceutical. W.M.R. has received reimbursement from a noncommercial entity: NIH (more than $\$ 100,001)$. S.L.R. does not have a financial relationship with a commercial entity that has an interest in the subject of this manuscript. H.S. does not have a financial relationship with a commercial entity that has an interest in the subject of this manuscript. S.C.S. has received reimbursement for serving on an advisory board with Hill-Rom (\$1,001$\$ 5,000)$, honorarium for lectures with Hill-Rom $(\$ 1,001-\$ 5,000)$, Astellas $(\$ 1001-\$ 5,000)$, and research with Expression Diagnostics $(\$ 50,001-$ $\$ 100,000)$. He has stock ownership or options with Vanguard Health Care Mutual Fund $(\$ 10,001-\$ 50,000)$, and has received reimbursement from a noncommercial entity: $\mathrm{NIH}$ (more than $\$ 100,001)$. W.v.B. does not have a financial relationship with a commercial entity that has an interest in the subject of this manuscript. J.V. does not have a financial relationship with a commercial entity that has an interest in the subject of this manuscript. E.A.M.V. does not have a financial relationship with a commercial entity that has an interest in the subject of this manuscript. E.J.L.E.V. does not have a financial relationship with a commercial entity that has an interest in the subject of this manuscript. W.W. does not have a financial relationship with a commercial entity that has an interest in the subject of this manuscript. M.S.W. has received reimbursement for serving on an advisory board with Genentech (up to $\$ 1,000$ ). She has received funding for research with Genentech $(\$ 10,001-\$ 50,000)$, Gilead/Corus $(\$ 50,001-\$ 100,000)$, Eurand $(\$ 10,001-\$ 50,000)$, and Johnson \& Johnson $(\$ 50,001-\$ 100,000)$. She has also received funding through a noncommercial entity: Cystic Fribrosis Therapeutics, Inc. (more than \$100,001). T.G.L. has received reimbursement for consultancies with Genentech $(\$ 1,001-\$ 5,000)$, and Actelion $(\$ 10,001-\$ 50,000)$. He has received reimbursement for expert testimony with Williams and Hunt $(\$ 5,001-\$ 10,000)$, funding for research with Altus (more than $\$ 100,001)$, Axcan Scandipharm (more than $\$ 100,001$ ), Gilead (more than $\$ 100,001)$, Inspire (more than $\$ 100,001)$, and MPEX $(\$ 50,001-$ $\$ 100,000)$. He has also received funding from noncommercial entities: $\mathrm{NIH} /$ NHLBI (more than $\$ 100,001$ ), Cystic Fibrosis Foundation (more than $\$ 100,001$ ), and the Margolis Foundation (more than $\$ 100,001$ ).

Acknowledgment: The conference attendees, speakers and participants of this roundtable discussion gratefully acknowledge the Ben B. and Ira M. Margolis Family Foundation of Utah for its generous support of the Lansdowne Conference, subsequent dialogs, and this publication. We thank Lynn Fukushima, Kristyn Packer and Jane Vroom for their assistance with conference logistics.

\section{References}

1. Aurora P, Edwards LB, Christie J, et al. Registry of the International Society for Heart and Lung Transplantation: eleventh official pediatric lung and heart/lung transplantation report-2008. J Heart Lung Transplant 2008;27:978-983.

2. Liou TG, Adler FR, Cox DR, Cahill BC. Lung transplantation and survival in children with cystic fibrosis. N Engl J Med 2007;357:2143-2152.

3. Allen J, Visner G. Lung transplantation in cystic fibrosis-primum non nocere? N Engl J Med 2007;357:2186-2188.
4. Sweet SC, Aurora P, Benden C, Wong JY, Goldfarb SB, Elidemir O, Woo MS, Mallory GB. Lung transplantation and survival in children with cystic fibrosis: solid statistics-flawed interpretation. Pediatr Transplant 2008;12:129-136.

5. Egan TM. Solid benefit of lung transplantation for some children with cystic fibrosis. Pediatr Transplant 2008;12:125-128.

6. Aurora P, Spencer H, Moreno-Galdó A. Lung transplantation in children with cystic fibrosis: a view from Europe. Am J Respir Crit Care Med 2008;177:935-936.

7. Aurora P, Whitehead, B, Wade A, Bowyer J, Whitmore P, Rees PG, Tsang VT, Elliott MJ, De Leval, M. Lung transplantation and life extension in children with cystic fibrosis. Lancet 1999;354:1591-1593.

8. Sharples L, Hathaway T, Dennis C, Caine N, Higenbottam T, Wallwork J. Prognosis of patients with cystic fibrosis awaiting heart and lung transplantation. J Heart Lung Transplant 1993;12:669-674.

9. Scott J, Higenbottam T, Hutter J, Hodson M, Stewart S, Penketh A, Wallwork J. Heart-lung transplantation for cystic fibrosis. Lancet 1988;2:192-194.

10. Noirclerc M, Chazalette JP, Metras D, Camboulives J, Vaillant A, Dumon JF, Carcassonne M. [Double lung transplantation. Report of the 1 st French case and comments on the 5 subsequent cases]. Ann Chir 1989;43:597-600.

11. Christie JD, Edwards LB, Aurora P, Dobbels F, Kirk R, Rahmel AO, Taylor DO, Kucheryavaya AY, Hertz MI. Registry of the International Society for Heart and Lung Transplantation: twenty-fifth official adult lung and heart/lung transplantation report-2008. J Heart Lung Transplant 2008;27:957-969.

12. Yankaskas JR, Mallory GB. Lung transplantation in cystic fibrosis: consensus conference statement. Chest 1998;113:217-226.

13. Kerem E, Reisman J, Corey M, Canny GJ, Levison H. Prediction of mortality in patients with cystic fibrosis. N Engl J Med 1992;326: 1187-1191.

14. Robinson W, Waltz DA. FEV(1) as a guide to lung transplant referral in young patients with cystic fibrosis. Pediatr Pulmonol 2000;30: 198-202.

15. Liou TG, Adler FR, FitzSimmons SC, Cahill BC, Hibbs JR, Marshall BC. Predictive 5-year survivorship model of cystic fibrosis. Am J Epidemiol 2001;153:345-352.

16. Mayer-Hamblett N, Rosenfeld M, Emerson J, Goss CH, Aitken ML. Developing cystic fibrosis lung transplant referral criteria using predictors of 2-year mortality. Am J Respir Crit Care Med 2002;166: $1550-1555$.

17. Rosenbluth DB, Wilson K, Ferkol T, Schuster DP. Lung function decline in cystic fibrosis patients and timing for lung transplantation referral. Chest 2004;126:412-419.

18. Belkin RA, Henig NR, Singer LG, Chaparro C, Rubenstein RC, Xie SX, Yee JY, Kotloff RM, Lipson DA, Bunin GR. Risk factors for death of patients with cystic fibrosis awaiting lung transplantation. Am J Respir Crit Care Med 2006;173:659-666.

19. Orens JB, Estenne M, Arcasoy S, Conte JV, Corris P, Egan JJ, Egan T, Keshavjee S, Knoop C, Kotloff R, et al. International guidelines for the selection of lung transplant candidates: 2006 update-a consensus report from the Pulmonary Scientific Council of the International Society for Heart and Lung Transplantation. J Heart Lung Transplant 2006;25:745-755.

20. Egan TM, Murray S, Bustami RT, Shearon TH, McCullough KP, Edwards LB, Coke MA, Garrity ER, Sweet SC, Heiney DA, et al. Development of the new lung allocation system in the United States. Am J Transplant 2006;6:1212-1227.

21. de Perrot M, Bonser RS, Dark J, Kelly RF, McGiffin D, Menza R, Pajaro O, Schueler S, Verleden GM. Report of the ISHLT Working Group on Primary Lung Graft Dysfunction part III: donor-related risk factors and markers. J Heart Lung Transplant 2005;24:1460-1467.

22. Oto T, Griffiths AP, Rosenfeldt F, Levvey BJ, Williams TJ, Snell GI. Early outcomes comparing Perfadex, Euro-Collins, and Papworth solutions in lung transplantation. Ann Thorac Surg 2006;82:18421848.

23. DeCampos KN, Keshavjee S, Liu M, Slutsky AS. Optimal inflation volume for hypothermic preservation of rat lungs. J Heart Lung Transplant 1998;17:599-607.

24. Aoe M, Okabayashi K, Cooper JD, Patterson GA. Hyperinflation of canine lung allografts during storage increases reperfusion pulmonary edema. J Thorac Cardiovasc Surg 1996;112:94-102.

25. Haniuda M, Hasegawa S, Shiraishi T, Dresler CM, Cooper JD, Patterson GA. Effects of inflation volume during lung preservation 
on pulmonary capillary permeability. J Thorac Cardiovasc Surg 1996; 112:85-93.

26. Wittwer T, Fehrenbach A, Meyer D, Brandes H, Albes J, Richter J, Wahlers T. Retrograde flush perfusion with low-potassium solutions for improvement of experimental pulmonary preservation. $J$ Heart Lung Transplant 2000;19:976-983.

27. Strüber M, Hohlfeld JM, Kofidis T, Warnecke G, Niedermeyer J, Sommer SP, Haverich A. Surfactant function in lung transplantation after 24 hours of ischemia: advantage of retrograde flush perfusion for preservation. J Thorac Cardiovasc Surg 2002;123:98-103.

28. Kofidis T, Strüber M, Warnecke G, Sommer S, Leyh RG, Balsam LB, Robbins RC, Haverich A. Antegrade versus retrograde perfusion of the donor lung: impact on the early reperfusion phase. Transpl Int 2003;16:801-805.

29. Curtis HJ, Bourke SJ, Dark JH, Corris PA. Lung transplantation outcome in cystic fibrosis patients with previous pneumothorax. $J$ Heart Lung Transplant 2005;24:865-869.

30. Wang Y, Kurichi JE, Blumenthal NP, Ahya VN, Christie JD, Pochettino A, Kaiser LR, Sonnad SS, Pollak ES. Multiple variables affecting blood usage in lung transplantation. J Heart Lung Transplant 2006;25:533-538.

31. Corno V, Dezza MC, Lucianetti A, Codazzi D, Carrara B, Pinelli D, Parigi PC, Guizzetti M, Strazzabosco M, Melzi ML et al. Combined double lung-liver transplantation for cystic fibrosis without cardiopulmonary by-pass. Am J Transplant 2007;7:2433-2438.

32. Barr ML, Kawut SM, Whelan TP, Girgis R, Böttcher H, Sonett J, Vigneswaran W, Follette DM, Corris PA. Report of the ISHLT Working Group on Primary Lung Graft Dysfunction part IV: recipient-related risk factors and markers. $J$ Heart Lung Transplant 2005;24:1468-1482.

33. Puri V, Patterson GA. Adult lung transplantation: technical considerations. Semin Thorac Cardiovasc Surg 2008;20:152-164.

34. Dalibon N, Geffroy A, Moutafis M, et al. Use of cardiopulmonary bypass for lung transplantation: a 10-year experience. J Cardiothorac Vasc Anesth 2006;20:668-672.

35. De Perrot M, Sekine Y, Fischer S, Waddell TK, McRae K, Liu M, Wigle DA, Keshavjee S. Interleukin-8 release during early reperfusion predicts graft function in human lung transplantation. $A m J$ Respir Crit Care Med 2002;165:211-215.

36. Kermeen FD, McNeil KD, Fraser JF, McCarthy J, Ziegenfuss MD, Mullany D, Dunning J, Hopkins PM. Resolution of severe ischemiareperfusion injury post-lung transplantation after administration of endobronchial surfactant. J Heart Lung Transplant 2007;26:850-856.

37. Ng CSH, Wan S, Yim APC. Pulmonary ischaemia-reperfusion injury: role of apoptosis. Eur Respir J 2005;25:356-363.

38. $\mathrm{Ng} \mathrm{CSH}$, Wan S, Arifi AA, Yim APC. Inflammatory response to pulmonary ischemia-reperfusion injury. Surg Today 2006;36:205-214.

39. Ovechkin AV, Lominadze D, Sedoris KC, Robinson TW, Tyagi SC, Roberts AM. Lung ischemia-reperfusion injury: implications of oxidative stress and platelet-arteriolar wall interactions. Arch Physiol Biochem 2007;113:1-12.

40. Amital A, Shitrit D, Raviv Y, Saute M, Bakal I, Medalion B, Kramer MR. Surfactant as salvage therapy in life threatening primary graft dysfunction in lung transplantation. Eur J Cardiothorac Surg 2009;35: 299-303.

41. Lee JC, Christie JD. Primary graft dysfunction. Proc Am Thorac Soc 2009;6:39-46.

42. Meyers BF, de la Morena M, Sweet SC, Trulock EP, Guthrie TJ, Mendeloff EN, Huddleston C, Cooper JD, Patterson GA. Primary graft dysfunction and other selected complications of lung transplantation: a single-center experience of 983 patients. $J$ Thorac Cardiovasc Surg 2005;129:1421-1429.

43. Huang HJ, Yusen RD, Meyers BF, Walter MJ, Mohanakumar T, Patterson GA, Trulock EP, Hachem RR. Late primary graft dysfunction after lung transplantation and bronchiolitis obliterans syndrome. Am J Transplant 2008;8:2454-2462.

44. Novick RJ, Bennett LE, Meyer DM, Hosenpud JD. Influence of graft ischemic time and donor age on survival after lung transplantation. J Heart Lung Transplant 1999;18:425-431.

45. Venkateswaran RV, Dronavalli V, Lambert PA, Steeds RP, Wilson IC, Thompson RD, Mascaro JG, Bonser RS. The proinflammatory environment in potential heart and lung donors: prevalence and impact of donor management and hormonal therapy. Transplantation 2009;88:582-588.

46. de Perrot M, Liu M, Waddell TK, Keshavjee S. Ischemia-reperfusioninduced lung injury. Am J Respir Crit Care Med 2003;167:490-511.
47. Kaneda H, Waddell TK, De Perrot M, Bai XH, Gutierrez C, Arenovich T, Chaparro C, Liu M, Keshavjee S. Pre-implantation multiple cytokine mRNA expression analysis of donor lung grafts predicts survival after lung transplantation in humans. Am J Transplant 2006; 6:544-551.

48. Anraku M, Cameron MJ, Waddell TK, Liu M, Arenovich T, Sato M, Cypel M, Pierre AFde Perrot M, Kelvin DJ, et al. Impact of human donor lung gene expression profiles on survival after lung transplantation: a case-control study. Am J Transplant 2008;8:2140-2148.

49. Barklin A. Systemic inflammation in the brain-dead organ donor. Acta Anaesthesiol Scand 2009;53:425-435.

50. Shargall Y, Guenther G, Ahya VN, Ardehali A, Singhal A, Keshavjee S. Report of the ISHLT Working Group on Primary Lung Graft Dysfunction part VI: treatment. J Heart Lung Transplant 2005;24: 1489-1500.

51. Fischer S, Bohn D, Rycus P, Pierre AF, de Perrot M, Waddell TK, Keshavjee S. Extracorporeal membrane oxygenation for primary graft dysfunction after lung transplantation: analysis of the Extracorporeal Life Support Organization (ELSO) registry. J Heart Lung Transplant 2007;26:472-477.

52. Huddleston CB, Mendeloff EN, Cohen AH, Sweet SC, Balzer DT, Mallory Jr GB. Lung retransplantation in children. Ann Thorac Surg 1998;66:199-203, discussion 203-204.

53. Wekerle T, Klepetko W, Wisser W, Senbaklavaci O, Moidl R, Hiesmayer M, Tschernko E, Wolner E. Lung retransplantation: institutional report on a series of twenty patients. J Heart Lung Transplant 1996;15:182-189.

54. Aigner C, Jaksch P, Taghavi S, Lang G, Hoda A, Wisser W, Klepetko W. Pulmonary retransplantation: is it worth the effort? A long-term analysis of 46 cases. $J$ Heart Lung Transplant 2008;27:60-65.

55. Gupta MR, Valentine VG, Walker Jr JE, Lombard GA, LaPlace SG, Seoane L, Taylor DE, Dhillon GS. Clinical spectrum of gram-positive infections in lung transplantation. Transpl Infect Dis 2009 [Accessed September 20, 2009]. Available at: http://www.ncbi.nlm.nih.gov/ pubmed/19659672.

56. Arthurs SK, Eid AJ, Deziel PJ, Marshall WF, Cassivi SD, Walker RC, Razonable RR. The impact of invasive fungal diseases on survival after lung transplantation. Clin Transplant 2009 [Accessed September 20, 2009]. Available at: http://www.ncbi.nlm.nih.gov/pubmed/ 19712081

57. Kerschner H, Jaksch P, Karigl G, Popow-Kraupp T, Klepetko W, Puchhammer-Stöckl E. Cytomegalovirus DNA load patterns developing after lung transplantation are significantly correlated with longterm patient survival. Transplantation 2009;87:1720-1726.

58. Danziger-Isakov LA, Worley S, Michaels MG, Arrigain S, Aurora P, Ballmann M, Boyer D, Conrad C, Eichler I, Elidemir O, et al. The risk, prevention, and outcome of cytomegalovirus after pediatric lung transplantation. Transplantation 2009;87:1541-1548.

59. Dobbin C, Maley M, Harkness J, Benn R, Malouf M, Glanville A, Bye P. The impact of pan-resistant bacterial pathogens on survival after lung transplantation in cystic fibrosis: results from a single large referral centre. J Hosp Infect 2004;56:277-282.

60. Hadjiliadis D, Steele MP, Chaparro C, Singer LG, Waddell TK, Hutcheon MA, Davis RD, Tullis DE, Palmer SM, Keshavjee S. Survival of lung transplant patients with cystic fibrosis harboring panresistant bacteria other than Burkholderia cepacia, compared with patients harboring sensitive bacteria. J Heart Lung Transplant 2007;26:834-838.

61. Sopirala MM, Pope-Harman A, Nunley DR, Moffatt-Bruce S, Ross P, Martin SI. Multidrug-resistant Acinetobacter baumannii pneumonia in lung transplant recipients. J Heart Lung Transplant 2008;27:804807.

62. Snell GI, de Hoyos A, Krajden M, Winton T, Maurer JR. Pseudomonas cepacia in lung transplant recipients with cystic fibrosis. Chest 1993; 103:466-471.

63. Singh N. Fungal infections in the recipients of solid organ transplantation. Infect Dis Clin North Am 2003;17:113-134. (viii.).

64. Laube BL, Karmazyn YJ, Orens JB, Mogayzel PJ. Albuterol improves impaired mucociliary clearance after lung transplantation. $J$ Heart Lung Transplant 2007;26:138-144.

65. Herve P, Silbert D, Cerrina J, Simonneau G, Dartevelle P. Impairment of bronchial mucociliary clearance in long-term survivors of heart/ lung and double-lung transplantation. The Paris-Sud Lung Transplant Group. Chest 1993;103:59-63.

66. Herold U, Jakob H, Kamler M, Thiele R, Tochtermann U, Weinmann J, Motsch J, Gebhard MM, Hagl S. Interruption of bronchial 
circulation leads to a severe decrease in peribronchial oxygen tension in standard lung transplantation technique. Eur J Cardiothorac Surg 1998;13:176-183.

67. D'Ovidio F, Singer LG, Hadjiliadis D, Pierre A, Waddell TK, de Perrot M, Hutcheon M, Miller L, Darling G, Keshavjee S. Prevalence of gastroesophageal reflux in end-stage lung disease candidates for lung transplant. Ann Thorac Surg 2005;80:1254-1260.

68. D'Ovidio F, Mura M, Tsang M, Waddell TK, Hutcheon MA, Singer LG, Hadjiliadis D, Chaparro C, Gutierrez C, Pierre A, et al. Bile acid aspiration and the development of bronchiolitis obliterans after lung transplantation. J Thorac Cardiovasc Surg 2005;129:1144-1152.

69. Cantu E, Appel JZ, Hartwig MG, Woreta H, Green C, Messier R, Palmer SM, Davis Jr RD. J. Maxwell Chamberlain memorial paper. Early fundoplication prevents chronic allograft dysfunction in patients with gastroesophageal reflux disease. Ann Thorac Surg 2004;78: 1142-1151, discussion 1142-1151.

70. Davis Jr RD, Lau CL, Eubanks S, Messier RH, Hadjiliadis D, Steele MP, Palmer SM. Improved lung allograft function after fundoplication in patients with gastroesophageal reflux disease undergoing lung transplantation. $J$ Thorac Cardiovasc Surg 2003;125:533-542.

71. Palmer SM, Miralles AP, Howell DN, Brazer SR, Tapson VF, Davis RD. Gastroesophageal reflux as a reversible cause of allograft dysfunction after lung transplantation. Chest 2000;118:1214-1217.

72. Weiss ES, Allen JG, Meguid RA, et al. The center effect in lung transplantation: a volume outcome analysis of over 10,000 cases [Accessed July 20, 2009]. Available at: http://www.sts.org/2009webcast/ shows/weiss $2 /$ index.html

73. World Health Organization. WHO adherence to long-term therapies: evidence for action. 2003. [Accessed September 18, 2009]. Available at: http://www.who.int/chp/knowledge/publications/adherence_report/ en/index.html

74. Dalcin PTR, Rampon G, Pasin LR, Ramon GM, Abrahão CLO, Oliveira VZ. Adherence to treatment in patients with cystic fibrosis. J Bras Pneumol 2007;33:663-670.

75. Patterson JM, Wall M, Berge J, Milla C. Gender differences in treatment adherence among youth with cystic fibrosis: Development of a new questionnaire. J Cyst Fibros 2008;7:154-164.

76. McNamara PS, McCormack P, McDonald AJ, Heaf L, Southern KW. Open adherence monitoring using routine data download from an adaptive aerosol delivery nebuliser in children with cystic fibrosis. J Cyst Fibros 2009;8:258-263.

77. Dew MA, DiMartini AF, De Vito Dabbs A, Myaskovsky L, Steel J, Unruh M, Switzer GE, Zomak R, Kormos RL, Greenhouse JB. Rates and risk factors for nonadherence to the medical regimen after adult solid organ transplantation. Transplantation 2007;83:858-873.

78. De Geest S, Dobbels F, Fluri C, Paris W, Troosters T. Adherence to the therapeutic regimen in heart, lung, and heart-lung transplant recipients. J Cardiovasc Nurs 2005; 20(5, Suppl)S88-S98.

79. Dew MA, DiMartini AF, De Vito Dabbs A, Zomak R, De Geest S, Dobbels F, Myaskovsky L, Switzer GE, Unruh M, Steel JL, et al. Adherence to the medical regimen during the first two years after lung transplantation. Transplantation 2008;85:193-202.

80. Wells A, Faro A. Special considerations in pediatric lung transplantation. Semin Respir Crit Care Med 2006;27:552-560.

81. Wessels-Bakker MJ, Nossent GD, van de Graaf EA. Factors influencing medication adherence after lung transplantation. $J$ Heart Lung Transplant 2006;25:S178-S178.

82. De Geest S, Abraham I, Moons P, Vandeputte M, Van Cleemput J, Evers G, Daenen W, Vanhaecke J. Late acute rejection and subclinical noncompliance with cyclosporine therapy in heart transplant recipients. J Heart Lung Transplant 1998;17:854-863.

83. Irani S, Seba P, Speich R, Boehler A. Medication errors: an important component of nonadherence to medication in an outpatient population of lung transplant recipients. Am J Transplant 2007;7:2561-2566.

84. Dobbels F, Vanhaecke J, Desmyttere A, Dupont L, Nevens F, De Geest S. Prevalence and correlates of self-reported pretransplant nonadherence with medication in heart, liver, and lung transplant candidates. Transplantation 2005;79:1588-1595.

85. Vermeulen KM, van der Bij W, Erasmus ME, Duiverman EJ, Koëter GH, TenVergert EM. Improved quality of life after lung transplantation in individuals with cystic fibrosis. Pediatr Pulmonol 2004; $37: 419-426$

86. Slieker MG, Uiterwaal CSPM, Sinaasappel M, Heijerman HGM, van der Laag J, van der Ent CK. Birth prevalence and survival in cystic fibrosis: a national cohort study in the Netherlands. Chest 2005;128: 2309-2315.
87. Kulich M, Rosenfeld M, Goss $\mathrm{CH}$, Wilmott R. Improved survival among young patients with cystic fibrosis. J Pediatr 2003;142:631636.

88. Davis PB. Cystic fibrosis since 1938. Am J Respir Crit Care Med 2006; 173:475-482.

89. Cystic Fibrosis Foundation. Cystic fibrosis foundation patient registry. Bethesda, Maryland; 2008. Available at: http://www.cff.org/ UploadedFiles/research/ClinicalResearch/2007-Patient-Registry-Report. pdf.

90. Gibson RL, Burns JL, Ramsey BW. Pathophysiology and management of pulmonary infections in cystic fibrosis. Am J Respir Crit Care Med 2003;168:918-951.

91. Yankaskas JR, Marshall BC, Sufian B, Simon RH, Rodman D. Cystic fibrosis adult care: consensus conference report. Chest 2004;125:1S39S.

92. Cystic Fibrosis Foundation. Clinical practice guidelines for cystic fibrosis. Bethesda, Maryland; 1997.

93. Llorente R, Bousonogarcia C, Diazmartin J. Treatment compliance in children and adults with cystic fibrosis. $J$ Cyst Fibros 2008;7:359367.

94. Liou TG, Adler FR, Cahill BC, FitzSimmons SC, Huang D, Hibbs JR, Marshall BC. Survival effect of lung transplantation among patients with cystic fibrosis. JAMA 2001;286:2683-2689.

95. Lai H, Kosorok MR, Laxova A, Makholm LM, Farrell PM. Delayed diagnosis of US females with cystic fibrosis. Am J Epidemiol 2002;156: 165-173.

96. Rosenfeld M, Davis R, FitzSimmons S, Pepe M, Ramsey B. Gender gap in cystic fibrosis mortality. Am J Epidemiol 1997;145:794-803.

97. Qvist E, Jalanko H, Holmberg C. Psychosocial adaptation after solid organ transplantation in children. Pediatr Clin North Am 2003;50: 1505-1519.

98. Ware JE, Sherbourne CD. The MOS 36-item short-form health survey (SF-36). I. Conceptual framework and item selection. Med Care 1992; 30:473-483.

99. Mahler DA, Mackowiak JI. Evaluation of the short-form 36-item questionnaire to measure health-related quality of life in patients with COPD. Chest 1995;107:1585-1589.

100. Abbott J, Hart A, Morton AM, Dey P, Conway SP, Webb AK. Can health-related quality of life predict survival in adults with cystic fibrosis? Am J Respir Crit Care Med 2009;179:54-58.

101. Modi AC, Quittner AL. Validation of a disease-specific measure of health-related quality of life for children with cystic fibrosis. $J$ Pediatr Psychol 2003;28:535-545.

102. Trulock EP, Christie JD, Edwards LB, Boucek MM, Aurora P, Taylor DO, Dobbels F, Rahmel AO, Keck BM, Hertz MI. Registry of the International Society for Heart and Lung Transplantation: twentyfourth official adult lung and heart-lung transplantation report-2007. $J$ Heart Lung Transplant 2007;26:782-795.

103. Caine N, Sharples LD, Dennis C, Higenbottam TW, Wallwork J. Measurement of health-related quality of life before and after heart-lung transplantation. J Heart Lung Transplant 1996;15:10471058.

104. TenVergert EM, Essink-Bot ML, Geertsma A, van Enckevort PJ, de Boer WJ, van der Bij W. The effect of lung transplantation on healthrelated quality of life: a longitudinal study. Chest 1998;113:358-364.

105. Cohen L, Littlefield C, Kelly P, Maurer J, Abbey S. Predictors of quality of life and adjustment after lung transplantation. Chest 1998; 113:633-644.

106. Limbos MM, Chan CK, Kesten S. Quality of life in female lung transplant candidates and recipients. Chest 1997;112:1165-1174.

107. Limbos MM, Joyce DP, Chan CK, Kesten S. Psychological functioning and quality of life in lung transplant candidates and recipients. Chest 2000;118:408-416.

108. Dennis C, Caine N, Sharples L, Smyth R, Higenbottam T, Stewart S, Wreghitt T, Large S, Wells FC, Wallwork J. Heart-lung transplantation for end-stage respiratory disease in patients with cystic fibrosis at Papworth Hospital. J Heart Lung Transplant 1993;12:893-902.

109. Ramsey SD, Patrick DL, Lewis S, Albert RK, Raghu G. Improvement in quality of life after lung transplantation: a preliminary study. The University of Washington Medical Center Lung Transplant Study Group. J Heart Lung Transplant 1995;14:870-877.

110. Ramsey SD, Patrick DL, Albert RK, Larson EB, Wood DE, Raghu G. The cost-effectiveness of lung transplantation. A pilot study. University of Washington Medical Center Lung Transplant Study Group. Chest 1995;108:1594-1601. 
111. Quittner AL, Cruz I, Modi A, Marciel K. Health-related quality of life instruments for adolescents with chronic diseases. In: Tolle L, O'Donohue WT, eds. Behavioral approaches to chronic disease in adolescence: a guide to integrative care. 1st ed. New York: Springer; 2009.

112. Wray J, Radley-Smith R, Yacoub M. Effect of cardiac or heart-lung transplantation on the quality of life of the paediatric patient. Qual Life Res 1992;1:41-46.

113. Goss $\mathrm{CH}$, Quittner AL. Patient-reported outcomes in cystic fibrosis. Proc Am Thorac Soc 2007;4:378-386.

114. Retsch-Bogart GZ, Quittner AL, Gibson RL, Oermann CM, McCoy KS, Montgomery AB, Cooper PJ. Efficacy and safety of inhaled aztreonam lysine for airway pseudomonas in cystic fibrosis. Chest 2009;135:1223-1232.

115. Turner RR, Quittner AL, Parasuraman BM, Kallich JD, Cleeland CS. Patient-reported outcomes: instrument development and selection issues. Value Health 2007;10:S86-S93.

116. McCoy KS, Quittner AL, Oermann CM, Gibson RL, Retsch-Bogart GZ, Montgomery AB. Inhaled aztreonam lysine for chronic airway Pseudomonas aeruginosa in cystic fibrosis. Am J Respir Crit Care Med 2008;178:921-928.

117. Palermo TM, Long AC, Lewandowski AS, Drotar D, Quittner AL, Walker LS. Evidence-based assessment of health-related quality of life and functional impairment in pediatric psychology. J Pediatr Psychol 2008;33:983-996, discussion 997-998.

118. Quittner AL, Buu A, Messer MA, Modi AC, Watrous M. Development and validation of the cystic fibrosis questionnaire in the United States: a health-related quality-of-life measure for cystic fibrosis. Chest 2005; 128:2347-2354.

119. Woo MS, Fukushima L, Hsu E, Tse J, Quittner A. CF quality of life: comparison between pediatric CF lung transplant candidates and their caregivers. 2005.

120. Woo M, Fukushima L, Quittner A, Faro A. Lung transplant candidates vs. non-transplant CF patients: quality of life comparisons. Pediatr Pulmonol 2005;40:317.

121. Liou TG, Woo MS, Cahill BC. Lung transplantation for cystic fibrosis. Curr Opin Pulm Med 2006;12:459-463.

122. Gelber RD, Cole BF, Gelber S, Aron Goldhirsch. Comparing treatments using quality-adjusted survival: the Q-twist method. Am Stat 1995;49:161-169.

123. Quittner A, Barker D, Fukushima L, Woo M. A prospective study of health-related qualithy of life after lung transplant for CF. Pediatr Pulmonol 2008;43:397.

124. Auclair C. The fog of math. SVB: Newsletter of the Adult CF Committee of Quebec 2007;31:5.

125. Sawicki GS, Dill EJ, Asher D, Sellers DE, Robinson WM. Advance care planning in adults with cystic fibrosis. J Palliat Med 2008;11: 1135-1141.

126. Lowton K. "Double or quits": perceptions and management of organ transplantation by adults with cystic fibrosis. Soc Sci Med 2003;56: 1355-1367.

127. Conway SP. Transition from paediatric to adult-orientated care for adolescents with cystic fibrosis. Disabil Rehabil 1998;20:209-216.

128. Gillett G. Ethics of surgical innovation. Br J Surg 2001;88:897-898.

129. Linden PK. History of solid organ transplantation and organ donation. Crit Care Clin 2009;25:165-184. (ix.).

130. Reitsma AM, Moreno JD. Ethics of innovative surgery: US surgeons' definitions, knowledge, and attitudes. J Am Coll Surg 2005;200:103110

131. Reitsma AM, Moreno JD. Ethical regulations for innovative surgery: the last frontier? J Am Coll Surg 2002;194:792-801.

132. Iribarne A, Russo MJ, Davies RR, Hong KN, Gelijns AC, Bacchetta MD, D’Ovidio F, Arcasoy S, Sonett JR. Despite decreased wait-list times for lung transplantation, lung allocation scores continue to increase. Chest 2009;135:923-928.

133. Levine SM, Angel LF. Is the lung allocation score working? a qualified: yes. Chest 2009;135:890-892.

134. Aurora P, Wade A, Whitmore P, Whitehead B. A model for predicting life expectancy of children with cystic fibrosis. Eur Respir J 2000;16: 1056-1060.

135. Aurora P, Gassas A, Ehtisham S, Whitehead B, Whitmore P, Rees PG, Tsang VT, Elliott MJ, De Leval M. The effect of prelung transplant clinical status on post-transplant survival of children with cystic fibrosis. Eur Respir J 2000;16:1061-1064.

136. Evans RW, Kitzmann DJ. Contracting for services: liver transplantation in the era of mismanaged care. Clin Liver Dis 1997;1:287-303. (viii.).

137. Marshall B, Swearingen JP. Complexities in transplant revenue management. Prog Transplant 2007;17:94-98.

138. Hofer M, Benden C, Inci I, Schmid C, Irani S, Speich R, Weder W, Boehler A. True survival benefit of lung transplantation for cystic fibrosis patients: the Zurich experience. J Heart Lung Transplant 2009;28:334-339.

139. Fisher RA. The design of experiments. Edinburgh: Oliver and Boyde; 1935.

140. Leighton G, McKinlay PL. Milk consumption and the growth of school children: report on an investigation in Lanarkshire schools. Edinburgh: Department of Health for Scotland; 1930.

141. Cox DR. Planning of experiments. New York: Wiley; 1958.

142. Piantadosi S. Clinical trials: a methodologic perspective. New York: Wiley; 1997.

143. Hosenpud JD, Bennett LE, Keck BM, Edwards EB, Novick RJ. Effect of diagnosis on survival benefit of lung transplantation for end-stage lung disease. Lancet 1998;351:24-27.

144. De Meester J, Smits JM, Persijn GG, Haverich A. Listing for lung transplantation: life expectancy and transplant effect, stratified by type of end-stage lung disease, the Eurotransplant experience. J Heart Lung Transplant 2001;20:518-524.

145. Liou TG, Adler FR, Huang D. Use of lung transplantation survival models to refine patient selection in cystic fibrosis. Am J Respir Crit Care Med 2005;171:1053-1059.

146. United Network for Organ Sharing. Organ donation and transplantation [Accessed September 21, 2009]. Available at: http://www.unos.org/data/

147. Maurer JR. Patient selection for lung transplantation. JAMA 2001;286: 2720-2721.

148. Sweet SC, Faro A. Not so fast-don't deprive children with cystic fibrosis of the option for lung transplantation. Am J Respir Crit Care Med 2006;173:246-247, author reply 247-248.

149. Maish AB. Priorities for lung transplantation among patients with cystic fibrosis. JAMA 2002;287:1524, author reply 1524-1525.

150. Liou TG, Adler FR, Cahill BC, FitzSimmons SC, Huang D, Hibbs JR, Marshall BC, Maish AB, Maurer JR. Priorities for lung transplantation among patients with cystic fibrosis. JAMA 2002;287:1523-1524, author reply $1524-1525$.

151. Sagel SD, Chmiel JF, Konstan MW. Sputum biomarkers of inflammation in cystic fibrosis lung disease. Proc Am Thorac Soc 2007;4: 406-417.

152. Ordonez CL, Henig NR, Mayer-Hamblett N, Accurso FJ, Burns JL, Chmiel JF, Daines CL, Gibson RL, McNamara S, Retsch-Bogart GZ, et al. Inflammatory and microbiologic markers in induced sputum after intravenous antibiotics in cystic fibrosis. Am J Respir Crit Care Med 2003;168:1471-1475.

153. Mayer-Hamblett N, Aitken ML, Accurso FJ, Kronmal RA, Konstan MW, Burns JL, Sagel SD, Ramsey BW. Association between pulmonary function and sputum biomarkers in cystic fibrosis. Am J Respir Crit Care Med 2007;175:822-828. 